\title{
Study on Influencing Factors of Postoperative Recurrence of Lumbar Disc Herniation Treated by Percutaneous Transforaminal Endoscopic Discectomy
}

\author{
LU WANG, CHAODONG ZHOU ${ }^{1}$, XIANHONG LIU ${ }^{1}$ AND DAXIONG FENG*
}

Department of Spine Surgery, The Affiliated Hospital of Southwest Medical University, Luzhou, Sichuan 646000, ${ }^{1}$ Department of Orthopedics, Chongqing General Hospital, Chongqing 400013, China

Wang et al.: Postoperative Recurrence of Lumbar Disc Herniation by Percutaneous Transforaminal Endoscopic Discectomy

To investigate the influencing factors of percutaneous perforation for lumbar disc herniation. A total of 65 patients with recurrent lumbar disc herniation treated in our hospital from January 2015 to December 2020 (observation group) were selected and 130 patients without recurrence were selected as the control group. 65 patients with recurrent lumbar disc herniation were divided into Group $A(n=32)$ and Group B (n=33). The patients in Group A were treated with percutaneous transforaminal endoscopic lumbar discectomy and the patients in Group B were treated with traditional spinal canal decompression, and nucleus pulposus removal cage fusion and internal fixation. The operation, Japanese orthopaedic association score and Oswestry disability index of the two groups were observed. Logistic regression analysis showed that age, body mass index, Pfirrman classification, incomplete removal of nucleus pulposus during operation and postoperative sedentary work or heavy physical work were the influencing factors of postoperative recurrence (Odds ratio $=1.667,1.545,1.831,2.038$ and $1.925, p<0.05)$. The operation time, intraoperative blood loss and hospitalization time in Group A were (50.51 \pm 3.39$) \mathrm{min},(\mathbf{4 5 . 5 1} \pm \mathbf{3 . 1 5}) \mathrm{ml}$ and (12.03 \pm 3.22$) \mathrm{d}$, respectively, which were significantly less than those in Group B $(\mathbf{p}<\mathbf{0 . 0 5})$. Japanese orthopaedic association score at 3 mo after operation in Group A was $(25.51 \pm 2.03)$ points, which was significantly higher than that in Group B $(\mathbf{p}<0.05)$, while Oswestry disability index was $(\mathbf{2 0 . 0 3} \pm \mathbf{2 . 6 2}) \%$, which was significantly lower than that in Group B $(\mathbf{p}<\mathbf{0 . 0 5})$. The visual analogue scale score of Group A at 3 mo after operation was $(2.50 \pm 0.44)$ points, which was significantly lower than that of Group B $(\mathbf{p}<\mathbf{0 . 0 5})$. Patients with recurrence after percutaneous transforaminal endoscopic treatment effect are still good.

Key words: Percutaneous transforaminal endoscopy, lumbar disc herniation, postoperative recurrence, intervertebral disc

Lumbar disc herniation is a common disease in the department of orthopedics, mainly in young and middleaged most of them are males. At present, it is believed that the long-term incorrect waist habit is an important reason for the occurrence of this disease. At present, there are many clinical methods for the treatment of lumbar disc. About $80 \%$ of patients can be alleviated by conservative treatment, but nearly $20 \%$ of patients need to carry out surgical treatment ${ }^{[1]}$.

The traditional lumbar posterior approach fenestration discectomy has great trauma and slow postoperative recovery, which increases the life and economic pressure of patients and seriously affects the prognosis of patients. With the development of spinal endoscopy technology, intervertebral foramen endoscopy is widely used in clinical practice. It has the advantages of small trauma, accurate decompression and rapid postoperative recovery. But clinical also found that although percutaneous transforaminal endoscopic treatment of lumbar disc herniation has significant effect, there are still some patients with recurrence and the factors affecting postoperative recurrence are different ${ }^{[2]}$. This study analyzed the influencing factors of postoperative recurrence in patients with lumbar disc herniation, in order to provide guidance and basis, now reported as below.

*Address for correspondence

E-mail: fdxlzyxy2002@163.com 


\section{MATERIALS AND METHODS}

\section{General information:}

Selected 65 patients with recurrent lumbar disc herniation treated in our hospital from January 2015 to December 2020, Inclusion criteria-Diagnosis conforms to the standard of "Spinal surgery"; Single segment lesions; Patients with recurrence after percutaneous transforaminal endoscopic lumbar discectomy in our hospital; Patients and their family informed consent. Exclusion criteria-Combined with malignant tumors, important organ dysfunction, immune system diseases and other serious diseases; Combined with lumbar deformity, tuberculosis. At the same time, 130 patients without recurrence after percutaneous transforaminal lumbar discectomy in our hospital were selected as control group.

\section{Data collection:}

The clinical data of patients including age, gender, history of trauma, course of disease, working mode, clinical symptoms and surgical site were recorded. At the same time, the imaging data of patients before and after treatment were recorded. The collected data were input into the computer system and analyzed.

\section{Treatment group:}

According to the treatment plan, 65 patients with recurrent lumbar disc herniation were divided into Group A ( $\mathrm{n}=32)$ and Group B $(\mathrm{n}=33)$. The clinical data of the two groups were compared in Table 1, which was comparable.

\section{Treatment methods:}

Group A: Percutaneous transforaminal endoscopic treatment, patients take prone position, using C-arm to plan the puncture point and measure the puncture point and angle, anesthesia satisfaction with the use of No. 18 puncture needle in the perspective of the lateral facet of the superior articular process toward the intervertebral disc puncture, after the success of the needle core through the contrast needle toward the intervertebral disc injection methylene blue and iohexol mixture staining, to observe the morphology of the herniated nucleus pulposus and lesion annulus rupture. After satisfactory positioning, the facet joint was closed and the endoscope system was connected. The needle was inserted into the dead intervertebral disc and the skin was cut 6-7 mm. The expansion sleeve was inserted into the dead intervertebral disc. The ring saw was used to remove the upper facet of the herniated intervertebral disc and the $7 \mathrm{~mm}$ working sleeve was inserted after expanding the intervertebral foramen. The display system was connected to adjust the clarity of the intervertebral foramen phenomenon and the flocculent soft tissue in the surgical field was removed. The stained lesions of the nucleus pulposus were captured from the shallow to the deep by minimally invasive instruments. When necessary, the nucleus pulposus tissue could be ablated and the herniated intervertebral disc tissue was removed according to the depth of advancement. Until the decompression and release of the nerve root could be clearly observed, the working casing was removed and the suction device was used to attract the bleeding of the incision. After compression and hemostasis, a needle was sutured to the incision. The vital signs of patients were monitored in time after operation and the patients were guided by rehabilitation training. The patients were encouraged to get out of bed on the $2^{\text {nd }} d$ after operation.

TABLE 1: COMPARISON OF CLINICAL DATA BETWEEN GROUP A AND GROUP B

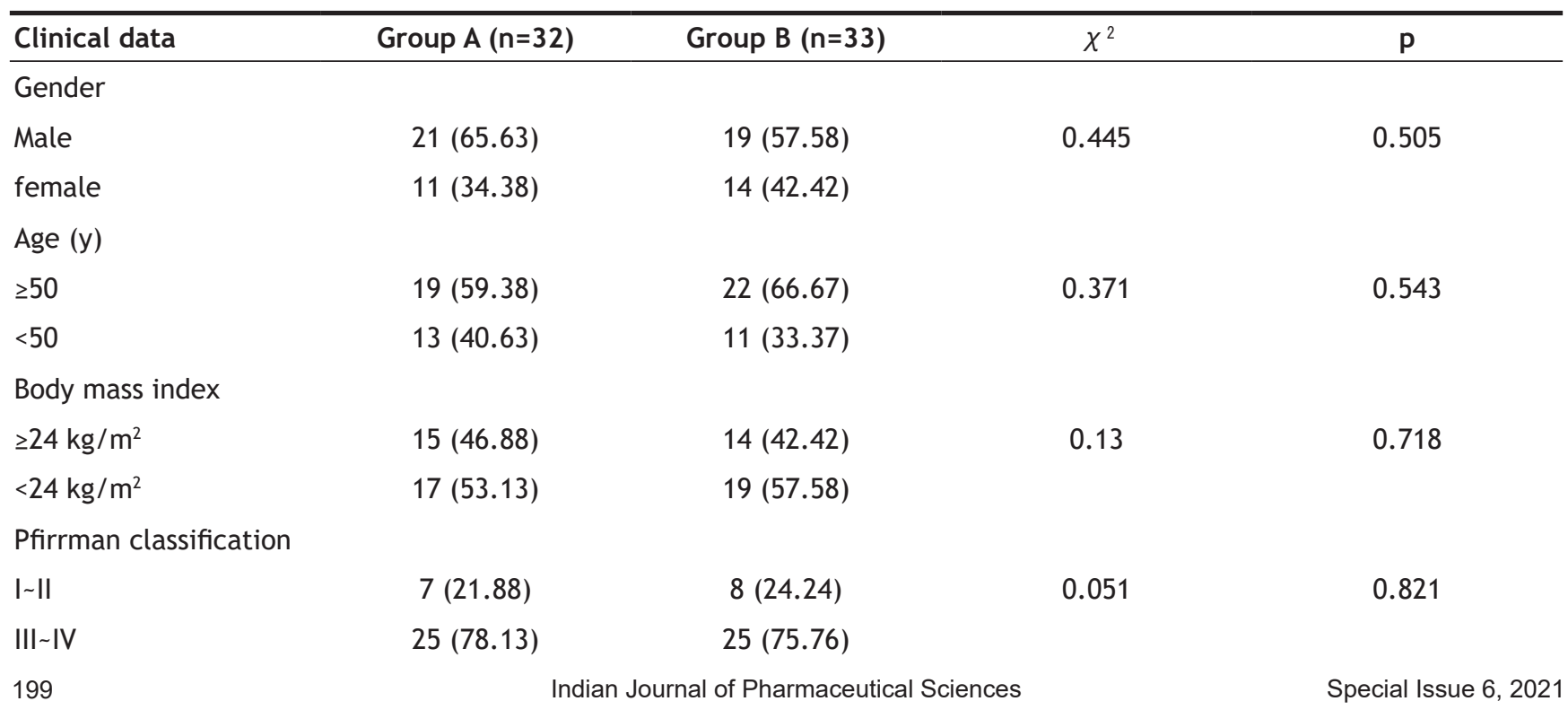


Diseased segment

$\begin{array}{lcccc}\text { L3-4 } & 8(25.00) & 6(18.18) & 0.477 & 0.788 \\ \text { L4-5 } & 20(62.50) & 22(66.67) & \\ \text { L5-S1 } & 4(12.50) & 5(15.15) & \end{array}$

Group B: The traditional spinal canal decompression and nucleus pulposus removal cage bone graft fusion and internal fixation were given and the prone position was taken after the patient was satisfied with anesthesia. The diseased intervertebral discs of the patients were located under the $\mathrm{C}$-arm. The $5 \mathrm{~cm}$ incision was cut along the median line after spinous process in the upper and lower parts of the diseased intervertebral discs. The skin and subcutaneous tissue were cut in turn and the extralaminous tissue was removed. Some laminas were removed and the ligamentum flavum was removed. The diseased nucleus pulposus tissue was removed. Thereafter, the nerve root is not tense and the height is slightly larger than normal to prevent nerve root injury caused by pulling. Embedding the previously resected large bone, adjusting the angle, posterior margin from the vertebral edge about $0.5 \sim 1.0 \mathrm{~cm}$ embedded with granular autologous bone cage. Pressurized fixation: Check whether there is residual tissue and compression. Remove compression after indwelling drainage tube, suture incision. Postoperative treatment: antibiotics were used within $5 \mathrm{~d}$ after operation and drainage was revoked when the drainage volume was less than $50 \mathrm{ml}$ within 1- $2 \mathrm{~d}$. The straight leg elevation of both lower limbs was practiced on the $3 \mathrm{rd} \mathrm{d}$ after operation. After 2-4 w, the braces were protected to get out of bed and avoid weight bearing within $100 \mathrm{~d}$.

\section{Evaluation criteria:}

Japanese Orthopaedic Association (JOA) score ${ }^{[3]}$ was used to evaluate the lumbar spine of patients. The scale was used to evaluate low back pain, gait, muscle strength and daily activities. The total score was 29 points. The higher the score, the better the lumbar function of patients; Oswestry Disability Index (ODI) [4] was used to evaluate lumbar function. The scale included pain, life, extract, walking, sitting and other 10 aspects. Each item had 6 options and scored 0-5 points. The total score was $=$ (actual score/maximum possible score) $\times 100 \%$. The higher the index, the more serious the dysfunction; Visual Analogue Scale (VAS) ${ }^{[5]}$ was used to evaluate the pain of patients. The score was $0-10$ and the higher the score was, the more severe the pain was.

\section{Statistical treatment:}

Statistical Package for the Social Sciences (SPSS)
22.0 software was used for data analysis. Normal distribution data were expressed as $(\overline{\mathrm{X}} \pm \mathrm{s})$. Differences between groups were compared using $t$ test. Count data were expressed as $\mathrm{n}(\%)$ and comparison between groups was performed using 2 tests. Logistic regression analysis was used for multivariate analysis. Test level: $\alpha=0.05$.

\section{RESULTS AND DISCUSSION}

In the observation group, age $\geq 50 \mathrm{y}$ old, body mass index $\geq 24 \mathrm{~kg} / \mathrm{m}^{2}$, Pfirrman grade III-V, incomplete removal of nucleus pulposus during operation, intraoperative fiber damage and proportion of patients engaged in sedentary station or heavy physical work after operation were significantly higher than those in the corresponding patients $(\mathrm{p}<0.05)$. As shown in Table 2 .

The above statistically significant indicators were used as independent variables and recurrence as dependent variables. The results showed that age, body mass index, Pfirrman classification, incomplete removal of nucleus pulposus during operation and postoperative sedentary station or heavy physical work were the influencing factors of postoperative recurrence (Odds Ratio $(\mathrm{OR})=1.667,1.545,1.831,2.038$ and 1.925, $\mathrm{p}<0.05)$, as shown in Table 3 .

The surgical time, intraoperative bleeding and hospitalization time in Group A were significantly less than Group B $(\mathrm{p}<0.05)$, as shown in Table 4.

There was no significant difference in JOA score and ODI index between Group A and Group B before operation $(p>0.05)$. The JOA score and ODI index of Group A and Group B were improved 3 mo after operation $(p<0.05)$. The JOA score of Group A at 3 mo after operation was significantly higher than that of Group B $(p<0.05)$, while the ODI index was significantly lower than that of Group B $(p<0.05)$. As shown in Table 5.

The difference between preoperative VAS scores in $A$ and $B$ was not significant $(\mathrm{p}>0.05)$; VAS scores decreased at 3 mo after A and B ( $>0.05)$; and VAS scores were significantly lower than $B(p>0.05)$. As shown in Table 6. 
TABLE 2: COMPARISON OF CLINICAL DATA BETWEEN THE OBSERVATION AND CONTROL GROUPS

\begin{tabular}{|c|c|c|c|c|}
\hline Clinical data & $\begin{array}{l}\text { Observation group } \\
(n=65)\end{array}$ & Control group $(n=130)$ & $\chi^{2}$ & $\mathrm{p}$ \\
\hline \multicolumn{5}{|l|}{ Gender } \\
\hline Male & $40(61.54)$ & $82(63.08)$ & 0.044 & 0.834 \\
\hline female & $25(38.46)$ & $48(36.92)$ & & \\
\hline \multicolumn{5}{|l|}{ Age $(y)$} \\
\hline$\geq 50$ & $41(63.08)$ & $41(31.54)$ & 17.688 & 0.000 \\
\hline$<50$ & $24(36.92)$ & $89(68.46)$ & & \\
\hline \multicolumn{5}{|l|}{ body mass index } \\
\hline$\geq 24 \mathrm{~kg} / \mathrm{m}^{2}$ & $29(44.62)$ & $32(24.62)$ & 8.063 & 0.005 \\
\hline$<24 \mathrm{~kg} / \mathrm{m}^{2}$ & $36(55.38)$ & $98(75.38)$ & & \\
\hline \multicolumn{5}{|c|}{ Pfirrman classification } \\
\hline $\mid \sim \|$ & $15(23.08)$ & $66(50.77)$ & 13.684 & 0.000 \\
\hline III IV & $50(76.92)$ & $64(49.23)$ & & \\
\hline \multicolumn{5}{|l|}{ Diseased segment } \\
\hline L3-4 & $14(21.54)$ & $26(20)$ & 0.324 & 0.850 \\
\hline L4-5 & $42(64.62)$ & $82(63.08)$ & & \\
\hline L5-S1 & $9(13.85)$ & $22(16.92)$ & & \\
\hline \multicolumn{5}{|c|}{$\begin{array}{l}\text { Intraoperative } \\
\text { enucleation of nucleus } \\
\text { pulposus }\end{array}$} \\
\hline Completely & $29(44.62)$ & $89(68.46)$ & 10.312 & 0.001 \\
\hline Not completely & $36(55.38)$ & $41(31.54)$ & & \\
\hline \multicolumn{5}{|l|}{$\begin{array}{l}\text { Intraoperative fiber } \\
\text { destruction }\end{array}$} \\
\hline Yes & $22(33.85)$ & $21(16.15)$ & 7.891 & 0.005 \\
\hline No & $43(66.15)$ & $109(83.85)$ & & \\
\hline $\begin{array}{l}\text { Long sitting and } \\
\text { standing or heavy } \\
\text { physical work after } \\
\text { operation }\end{array}$ & $25(38.46)$ & $11(8.46)$ & 25.908 & 0.000 \\
\hline
\end{tabular}

TABLE 3: MULTI-FACTOR ANALYSIS RESULTS

\begin{tabular}{|c|c|c|c|c|c|}
\hline Factor & b & SE & Wald's & $\mathrm{p}$ & OR $(95 \% \mathrm{Cl})$ \\
\hline Age & 0.511 & 0.143 & 12.769 & 0.000 & $1.667(1.260 \sim 2.206)$ \\
\hline Body mass index & 0.435 & 0.116 & 14.063 & 0.000 & $1.545(1.231 \sim 1.939)$ \\
\hline Pfirrman classification & 0.605 & 0.184 & 10.811 & 0.000 & 1.831 (1.277 2.626) \\
\hline $\begin{array}{l}\text { Intraoperative enucleation of } \\
\text { nucleus pulposus }\end{array}$ & 0.712 & 0.212 & 11.279 & 0.000 & $2.038(1.345 \sim 3.088)$ \\
\hline $\begin{array}{l}\text { Long sitting and standing or } \\
\text { heavy physical work after } \\
\text { operation }\end{array}$ & 0.655 & 0.165 & 15.758 & 0.000 & $1.925(1.393 \sim 2.660)$ \\
\hline
\end{tabular}


www.ijpsonline.com

TABLE 4: COMPARISON OF SURGERY IN GROUP A AND GROUP B

\begin{tabular}{lcccc}
\hline Group & Cases & Operation time $(\mathrm{min})$ & Intraoperative blood loss $(\mathrm{ml})$ & Hospital stay $(\mathrm{d})$ \\
\hline Group A & 32 & $50.51 \pm 3.39$ & $45.51 \pm 3.15$ & $12.03 \pm 3.22$ \\
Group B & 33 & $90.21 \pm 6.61$ & $103.44 \pm 10.15$ & $18.68 \pm 2.10$ \\
$\mathrm{t}$ & & -30.323 & -30.870 & -9.892 \\
P & & 0.000 & 0.000 & 0.000 \\
\hline
\end{tabular}

TABLE 5: COMPARISON OF JOA SCORES AND ODI BEFORE AND AFTER OPERATION

\begin{tabular}{|c|c|c|c|c|c|}
\hline \multirow[b]{2}{*}{ Group } & \multirow[b]{2}{*}{ Cases } & \multicolumn{2}{|c|}{ JOA score (points) } & \multicolumn{2}{|c|}{ ODI (\%) } \\
\hline & & Before operation & $\begin{array}{l}3 \text { mo after } \\
\text { operation }\end{array}$ & Before operation & $\begin{array}{l}3 \text { mo after } \\
\text { operation }\end{array}$ \\
\hline Group A & 32 & $11.15 \pm 3.32$ & $25.51 \pm 2.03^{*}$ & $62.21 \pm 7.06$ & $20.03 \pm 2.62^{*}$ \\
\hline Group B & 33 & $12.03 \pm 2.95$ & $20.11 \pm 2.19^{*}$ & $61.15 \pm 8.19$ & $31.54 \pm 3.03^{*}$ \\
\hline $\mathrm{t}$ & & -1.131 & 10.302 & 0.558 & -16.360 \\
\hline$P$ & & 0.263 & 0.000 & 0.579 & 0.000 \\
\hline
\end{tabular}

Note: *Compared with preoperative, $\mathrm{p}<0.05$; JOA: Japanese Orthopaedic Association; ODI: Oswestry Disability Index

TABLE 6: COMPARISON OF VAS SCORES BEFORE AND AFTER SURGERY IN THE TWO GROUPS

\begin{tabular}{lccc}
\hline \multirow{2}{*}{ roup } & Cases & \multicolumn{2}{c}{ VAS score (points) } \\
\cline { 3 - 4 } Group A & & Before operation & 3 mo after operation \\
Group B & 32 & $8.23 \pm 0.82$ & $2.50 \pm 0.44^{*}$ \\
$\mathrm{t}$ & 33 & $8.10 \pm 0.79$ & $4.12 \pm 0.60^{*}$ \\
$\mathrm{p}$ & & 0.651 & -12.382 \\
\hline
\end{tabular}

Note: *Compared with preoperative, $\mathrm{p}<0.05$; VAS: Visual Analogue Scale

Lumbar disc herniation is a common chronic disease in clinical practice. In recent years, the incidence rate has increased significantly and the incidence rate in China is $0.95 \%$. Generally, lumbar 5-sacral and lumbar 4-5 disc herniation are the most common diseases. The incidence rate of male patients is higher than that of female patients, which is mainly related to participation in heavy physical activity and the age of onset is mainly young and middle-aged ${ }^{[6]}$. On the one hand, the occurrence of lumbar disc herniation is related to immune factors. Anatomical studies have confirmed that the nucleus pulposus is a vascular free closed tissue. The proteoglycans in the nucleus pulposus through the annulus fibrosus will be recognized as antigens by the human body, forming an antigen-antibody complex, resulting in signs such as pain caused by immune response. On the other hand, it is believed that physical compression and physical stimulation are the direct causes of the disease. Compression will cause nerve displacement and demyelination changes around the ganglion, affecting the blood supply of nerve roots and congestion in the veins, resulting in countercurrent capillary ${ }^{[7]}$. Some scholars have pointed out that compression can cause inflammatory reactions around the nerve and the release of inflammatory factors can stimulate local pain and inflammatory lesions increase with the progression of the disease. The minimally invasive surgical treatment of lumbar disc herniation by intervertebral foramen mirror belongs to the minimally invasive surgical method under spinal endoscope. Through the endoscope and monitoring system, the minimally invasive instrument is used to puncture the intervertebral foramen and surrounding areas to achieve the diseased intervertebral disc and carry out the discectomy ${ }^{[8]}$. Although the application of intervertebral foramen mirror technology in patients with lumbar disc herniation is better and the postoperative recurrence rate is lower than that of other surgical methods, with the increase problem is still difficult to avoid with the increase of surgical cases. It is reported that the postoperative recurrence rate of patients with lumbar disc herniation treated by intervertebral foramen mirror is between 0 and $12 \%{ }^{[9]}$. In this study, the influencing factors of postoperative recurrence of lumbar disc herniation treated by percutaneous transforaminal endoscopic discectomy were analyzed. Logistic regression analysis showed that age, body mass index, Pfirrman classification, incomplete removal 
of nucleus pulposus during operation and long-term sitting or heavy physical work after operation were the influencing factors of postoperative recurrence of patients. The above factors should be paid attention to before operation.

Age is one of the influencing factors. With the increase of age, the water content of the nucleus pulposus and the elasticity of the intervertebral disc begin to decrease gradually. The degeneration of the people around $50 \mathrm{y}$ old is the most significant. Patients often have bone and soft tissue hyperplasia, spinal stenosis, osteoporosis and other diseases, which bring difficulties to diagnosis and treatment. After the difficulty of operation is relatively increased, it may cause the wrong judgment of the operator in the operation, which leads to incomplete decompression or damage to the normal structure. The study also found that the middle-aged and elderly people had slow tissue repair and low physical function, which may lead to postoperative recurrence and should be cautious in clinical application. Obesity patients with high body mass index have a high risk of postoperative recurrence. With the increase of body weight, the pressure on the intervertebral disc increases accordingly. The intervertebral disc degeneration speed is faster than that of the normal weight. The constant body weight of the patients after surgery leads to greater stress distributed in the remaining intervertebral disc tissue, which may occur earlier than that of the normal weight ${ }^{[10]}$. The higher the degree of intervertebral disc degeneration is, the worse the postoperative clinical efficacy is. If the degree of intervertebral disc degeneration is low, the quality of the intervertebral disc is still at a high level. After the removal of the nucleus pulposus, the remaining intervertebral disc tissue can still play a compensatory role and the probability of recurrence is low or no recurrence. If the degree of intervertebral disc degeneration is high, the remaining degeneration scores are less and the risk of recurrence is higher ${ }^{[11]}$. The incomplete removal of nucleus pulposus during operation is mainly that the residual nucleus pulposus tissue will be prominent again from the ruptured part of the annulus fibrosus, leading to the recurrence of the lesion. However, it should be noted in clinic that excessive removal may lead to intervertebral collapse ${ }^{[12]}$. After operation, longterm sitting or heavy-duty work will lead to recurrence. In the early postoperative period, the patient's tissue is in a slow repair stage and the local structure has not yet recovered to a steady state. Frequent or intense activities will make the lumbar spine continue or acute stress and the tissue healing is blocked. The nucleus pulposus can be re-protruded from the annulus fibrosus fissure and produce corresponding symptoms. The patients are lack of maintenance in the later period of cure and they are still long-term sitting or engaged in heavy duty work. The residual intervertebral disc tissue in the original segment is more prone to degeneration ${ }^{[13]}$.

In this study, the effect of traditional surgical treatment and endoscopic surgery for recurrent patients was compared again. The operation time, intraoperative blood loss and hospitalization time in Group A were significantly less than those in Group B, suggesting that percutaneous endoscopic surgery for recurrent patients with lumbar disc herniation can shorten the postoperative recovery time and reduce intraoperative blood loss. The JOA score in Group A was significantly higher than that in Group B 3 mo after operation, while the ODI was significantly lower than that in Group B, suggesting that percutaneous transforaminal endoscopic treatment for patients with postoperative recurrence of lumbar disc herniation was helpful to improve the lumbar function of patients. The VAS score of Group A was significantly lower than that of Group B at 3 mo after operation, suggesting that percutaneous transforaminal endoscopic treatment for patients with postoperative recurrence of lumbar disc herniation can significantly reduce the pain of postoperative patients. Open surgery will affect the stability of the lumbar spine and the treatment principle of surgical treatment of lumbar disc herniation is to relieve nerve compression, release the spinal canal now and maintain the integrity of the spinal canal as far as possible. Moreover, open surgery has great trauma to patients and slow postoperative recovery, which affects the therapeutic effect ${ }^{[14]}$. Intervertebral foraminoscopy in the treatment of recurrent lumbar disc herniation in patients with the application of the same trauma, less bleeding, postoperative recovery of patients with fast, can be endoscopic targeted removal of recurrent intervertebral disc, intraoperative repair of annulus fibrosus, so the minimum damage to the intervertebral disc tissue, help to maintain the activity of unlesioned intervertebral disc tissue, can maintain the normal height of intervertebral space, so as to reduce the occurrence of postoperative low back pain residual symptoms, restore the lumbar function of patients. At the same time, only a small amount of bone needs to be cut off during the operation, so it has a smaller impact on the stability of human spine. Surgical anesthesia only needs local anesthesia, so it can communicate with patients at any time, effectively ensuring the safety of the operation ${ }^{[15]}$.

This study found that the observation group age $\geq 50$ 
y old, body mass index $\geq 24 \mathrm{~kg} / \mathrm{m}^{2}$, Pfirrman grade III $\sim$, incomplete removal of nucleus pulposus, intraoperative fiber damage, engaged in sedentary station or heavy physical work after operation were significantly higher than the corresponding patients, suggesting that there are many factors affecting the recurrence of percutaneous transforaminal endoscopic lumbar discectomy. As a common clinical disease, lumbar disc herniation has many factors that affect the recurrence after surgical treatment. In this study, the risk factors for postoperative recurrence were found through screening, the reasons for postoperative recurrence were analyzed and the treatment experience was summarized to guide postoperative rehabilitation. At the same time, the efficacy of intervertebral foramen technology for patients with recurrent surgery was also analyzed, which provided a treatment basis for clinical rational treatment of patients with recurrent surgery. However, the number of patients in this study was small and there was a possibility that some influencing factors were omitted in the follow-up of patients after surgery. The evaluation of clinical efficacy was mainly concentrated in the short and medium term. Whether the factors affecting the clinical efficacy of patients after surgery in the conclusion were still meaningful in the long-term follow-up remains to be further studied.

In summary, the influencing factors of recurrence after percutaneous transforaminal endoscopic treatment of lumbar disc herniation include age, body mass index, Pfirrman classification, intraoperative discectomy and postoperative work. Patients with recurrence after percutaneous transforaminal endoscopic treatment effect is still good.

\section{Conflict of interests:}

The authors declared no conflicts of interest.

\section{REFERENCES}

1. Aihara T, Endo K, Sawaji Y, Suzuki H, Urushibara M, Kojima A, et al. Five-year reoperation rates and causes for reoperations following lumbar microendoscopic discectomy and decompression. Spine 2020;45(1):71-7.

2. Kang MS, Park JY, Kuh SU, Chin DK, Kim KS, Jin BH, et al. Preoperative radiographic clues for transdural disc herniation: Could it be predictable? Acta Neurochir 2019;161(12):2409-14.

3. Echt M, Holland R, Cezayirli P, de la Garza Ramos R, Hamad MK, Gelfand YJ, et al. 41. Surgical outcomes for upper lumbar disc herniations: A systematic review and meta-analysis of the literature. Spine J 2020;20(9):S20.
4. Burton CV, Kirkaldy-Willis WH, Yong-Hing K, Heithoff KB. Causes of failure of surgery on the lumbar spine. Clin Orthop Relat Res 1981;1(157):191-9.

5. Carragee EJ, Han MY, Suen PW, Kim D. Clinical outcomes after lumbar discectomy for sciatica: The effects of fragment type and anular competence. J Bone Joint Surg 2003;85(1):102-8.

6. Sansoni V, Perego S, Colombini A, Banfi G, Brayda-Bruno M, Lombardi G. Correction to: Interplay between low plasma RANKL and VDR-FokI polymorphism in lumbar disc herniation independently from age, body mass and environmental factors: A case-control study in the Italian population. Eur Spine J 2020;29(4):924.

7. Kienzler JC, Klassen PD, Miller LE, Assaker R, Heidecke V, Fröhlich $\mathrm{S}$, et al. Three-year results from a randomized trial of lumbar discectomy with annulus fibrosus occlusion in patients at high risk for reherniation. Acta Neurochir 2019;161(7):1389-96.

8. Kienzler JC, Fandino J, Van de Kelft E, Eustacchio S, Bouma GJ. Risk factors for early reherniation after lumbar discectomy with or without annular closure: Results of a multicenter randomized controlled study. Acta Neurochir 2021;163(1):25968 .

9. Kiss L, Varga PP, Szoverfi Z, Jakab G, Eltes PE, Lazary A. Answer to the Letter to the Editor of T. Xie et al. concerning "Indirect foraminal decompression and improvement in the lumbar alignment after percutaneous cement discoplasty" by Laszlo Kiss et al.(Eur Spine J;28(6):1441-1447). Eur Spine J 2020;29(1):200.

10. Yoo Y, Moon JY, Yoon S, Kwon SM, Sim SE. Clinical outcome of percutaneous lumbar foraminoplasty using a safety-improved device in patients with lumbar foraminal spinal stenosis. Medicine 2019;98(15):e15169.

11. Fukunaga T, Sasaki M, Bamba Y, Utsugi R, Matsumoto K, Umegaki M. A rare case of lumbar disc herniation mimicking lumbar discal cyst after percutaneous endoscopic lumbar discectomy. Interdiscip Neurosurg 2021;25(5):101131.

12. O’Neill SF, Fidelman JM, Haarup LS, Lund C, Konner MB. Low prevalence of end plate junction failure in danish patients with lumbar disc herniation. Sci Rep 2020;10(1):1-5.

13. Patel MS, Braybrooke J, Newey M, Sell P. A comparative study of the outcomes of primary and revision lumbar discectomy surgery. Bone Joint J 2013;95(1):90-4.

14. Kim KT, Lee DH, Cho DC, Sung JK, Kim YB. Preoperative risk factors for recurrent lumbar disk herniation in L5-S1. J Spinal Disord Tech 2015;28(10):E571-7.

15. Miwa S, Yokogawa A, Kobayashi T, Nishimura T, Igarashi $\mathrm{K}$, Inatani $\mathrm{H}$, et al. Risk Factors of Recurrent Lumbar Disk Herniation. J Spinal Disord Tech 2015;28(5):E265-9.

This is an open access article distributed under the terms of the Creative Commons Attribution-NonCommercial-ShareAlike 3.0 License, which allows others to remix, tweak, and build upon the work non-commercially, as long as the author is credited and the new creations are licensed under the identical terms

This article was originally published in a special issue, "Novel Therapeutic Approaches in Biomedicine and Pharmaceutical Sciences" Indian J Pharm Sci 2021:83(6) Spl Issue "198-204" 